\title{
Green Remanufacturing Engineering and Its Development Strategy in China
}

\begin{abstract}
Made in China 2025 proposes that "develop the remanufacturing industry vigorously, implement highend remanufacturing, smart remanufacturing, and inservice remanufacturing, advance the identification of remanufacturing products, and promote sustainable and healthy development of the manufacturing industry". Remanufacturing is an extension of the manufacturing industry chain, and it is an important part of advanced manufacturing and green manufacturing. The product function, technical performance, greenness and economy of the remanufacturing products are no worse than those of the new products. The cost of remanufacturing products is only about $50 \%$ of new products. Remanufacturing can save energy $60 \%$, and material $70 \%$, so the adverse impact on the environment is significantly reduced. At present, China's remanufacturing industry is developing rapidly, and the manufacturing pilot has been in full swing. Meanwhile, the policies and regulations, basic theory, key technology, and industry standards of remanufacturing have been continuously innovated and completed.
\end{abstract}

Keywords: green manufacturing, remanufacturing, circular economy

\section{Introduction}

Made in China 2025 proposes to adhere to the innovation driven, intelligent transformation, strengthening the foundation and green development. Green and intelligence are the main transformation directions of the manufacturing industry (Wang, 2015). The insistence of green development and the implementation of green manufacturing are the key moves. Remanufacturing as a typical form of green manufacturing, is an important direction of the transformation and upgrading of manufacturing industry. It is also an

Manuscript received January 15, 2016; accepted April 26, 2016

Bin-shi Xu ( $\square)$

National Priority Laboratory for Remanufacturing, Beijing 100072, China

Email: xubinshi@vip.sina.com important carrier to advance the green development, recycling development and low carbon development, and to promote the construction of ecological civilization. Remanufacturing as a burgeoning industry of national strategy, is not only the advanced form of renewable resources, but also the important measures of development of circular economy, and establishment of a resourcesaving and environment-friendly society (Xu, 2007, 2013).

\section{Connotation and characteristics of green remanufacturing}

Remanufacturing is the manufacturing process of the specialized repair or upgrading of waste products to make the quality of the remanufactured products achieve or superior to that of the original new products. Remanufacturing is an extension of the manufacturing industry chain, and it is also an important part of advanced manufacturing and green manufacturing.

The traditional equipment life cycle is "develop-usescrap", and the logistics is an open loop system. The life cycle of remanufactured equipment is "develop-use-scrapregenerate", and the logistics is a closed loop system. The emergence of remanufacturing improves the connotation of the product life cycle, making the product at the end of the life cycle, i.e., scrap stage, be no longer a solid waste.

The development of China's remanufacturing has experienced three main stages: The initiation of the industry, the scientific demonstration and the government advancing. After more than ten years of innovation and development, the remanufacturing with Chinese characteristics, as the feature of "size recovery and performance improvement" has formed. The remanufacturing with Chinese characteristics is developed based on the maintenance engineering and surface engineering. A large number of advanced techniques, such as life assessment techniques, composite surface engineering, nano-surface engineering and automated surface engineering are used to make the size precision of old parts recover to the requirements of the original design, and improve the quality and performance of the parts. The China's 
remanufacturing mode, based on size recovery and performance improvement, not only improve the product quality, but also significantly improve the remanufacturing rate of the old parts. The important feature of remanufactured products is that the quality is not worse than that of the new products. Remanufacturing can save energy $60 \%$, save material $70 \%$, and reduce air pollutant emissions by more than $80 \%$, compared with manufacturing a new one. Remanufacturing meeting the needs of great change of the traditional production and consumption patterns is an important way to realize the recycling of waste electrical and mechanical products. Remanufacturing is the advanced form of resource renewing, and the important measure of development of recycling economy, and building a resource-saving and environment-friendly society, but also an important carrier to advance the green development, low-carbon development, and to promote the construction of ecological civilization (Xu, Shi, \& Liu, 2012).

\section{The faced opportunities and challenges to develop green remanufacturing}

\subsection{Technical level}

The shortage of domestic resources and energy, energy saving and environmental protection requirements, and the growing scrap machinery equipment and the typical largescale and valuable equipment and parts put forward an urgent demand to remanufacturing mainly in the following aspects:

(1) In non-destructive dismantling technology of remanufacturing, considering the large-scale, complex and precision of waste electromechanical products of large machinery equipment, high-end numerical control machine and automobile, engineering machinery, how to develop total-dismantling equipment with rapidness, non-destructiveness and automation by using simulation and computer aided design is one of the keys to constrain the industrialization application scale of remanufacturing.

(2) In environmental protection cleaning of remanufacturing, one is to develop new cleaning materials, reducing the use of toxic substances and the negative impact on the environment and human. The second is to develop new cleaning equipment and optimize the cleaning process, improving the cleaning efficiency and reducing the cost of cleaning.

(3) In damage detection and life assessment of remanufacturing, firstly, the establishment of damaged information data base of waste parts with specific type is facing enormous challenges due to the difference of material, performance, structure, and service conditions of remanufacturing rough products. Secondly, how to extract the key parameters characterizing the quality level of the remanufactured rough products under the premise of no damage constrains the bottleneck of remaining life prediction. Thirdly, to study the effect and mechanism of heterogeneous interface is the most important part in the life assessment of remanufactured products. Lastly, the study of degradation mechanism of remanufactured products in different coupling effect of strong physical fields such as force field, magnetic field, electric field and thermal field is a challenge to the life assessment of remanufactured products (Xu, Dong, \& Shi, 2013).

(4) On the quality control of remanufacturing forming process, firstly, how to optimize the forming process according to the information of remanufacturing rough products and the automatic optimization of process parameters are facing big challenges. Secondly, the automatic and intelligent real-time monitoring of the implementation status in the process of remanufacturing to ensure that the coating is uniform, and combines well with the rough substrate, is the key and challenges to achieve quality control of remanufacturing process. Thirdly, there is still a big gap in intelligent control equipment. Lastly, a great challenge still exists in the intelligent forming process and material optimization (Xu, Dong, Zhu, \& Shi, 2012).

(5) On the intelligent technology of remanufacturing, the new techniques such as advanced surface engineering, electronic information and environmental protection, new materials and new process are used to improve the function or technical performance of old equipment by means of module replacement, structure transformation and performance optimization, in order to meet the higher demand of technology.

\subsection{Policy level}

(1) Social level: On the one hand, remanufacturing as a new concept has not been widely recognized by consumers and society. Many domestic consumers are still difficult to accept and use remanufactured products, and some people even make confused of remanufactured products and "second-hand goods". This is attributed to the lack of positive publicity on the remanufacturing and consumer attitudes formed in a long term. On the other hand, the sales channels of remanufactured products have not been fully established due to the lack of market cultivation, which affects the enthusiasm of the relevant enterprises to invest remanufacturing (Yang, 2014).

(2) Industrial level: First, various departments lack the overall consideration of remanufacturing industrial development. They did not consider the demand of sustainable development of manufacturing industry to remanufacturing. As a result, the progress and direction of the development of remanufacturing is not the same, and the development of the planning between the various places and enterprises does not connect, resulting in a number of contradictions and conflicts. Secondly, the market access mechanism and evaluation mechanism is lacked. The 
unqualified renovated products entering the after-sales service market by pretending to be pure new, not only affects the sales of normal remanufactured products, but also makes the real remanufacturing enterprises lose market competition advantage, leading to the market confusion. Thirdly, remanufacturing standards are not perfect. The lack of relevant standards and norms leads to that most of the enterprises do not construct corresponding quality control system in the key aspects such as old part testing and repairmen of manufacturing blank, resulting in the lack of scientific guarantee of product quality $(\mathrm{Li}, \mathrm{Shi}$, $\& \mathrm{Xu}, 2015)$.

(3) Enterprise level: Firstly, remanufacturing pilot enterprises do not have uniform and in-depth understanding of the remanufacturing. They are also not clear about the concepts and relations among remanufacturing, manufacturing and maintenance. Some enterprises directly remanufacture according to the manufacturing model, while some simply transplant repairing mode to remanufacturing, and consider that the expansion of the scale is the manufacturing, leading to the inaccurate positioning and target in the guidance of production process. Secondly, the relationship between production of new products and remanufacturing of waste products cannot be effectively managed. The foreign technology is simply copied, and the analysis of condition of the old parts and sales channels based on the national conditions is not given. There is no recognition of how to develop remanufacturing with Chinese characteristics based on the mature technology. Thirdly, some enterprises lack basic conditions such as professional and technical personnel, equipment and market cultivation of remanufacturing, resulting in be unable to get into the right track in a short time.

\section{Development trend of green remanufacturing engineering}

The shortage of domestic resources and energy, energy saving and environmental protection requirements, and the growing scrap machinery equipment and the typical largescale and valuable equipment and parts put forward an urgent demand to the development of equipment remanufacturing. The development trend of remanufacturing engineering includes the following five aspects:

(1) Apply high efficiency surface engineering technology to improve the remanufactured rate of waste products.

Wear and corrosion failure of product parts is an important factor that leads to the decline of product performance. The efficient surface engineering technology can be used to achieve the recovery or promotion of surface size and performance of failure parts, thus changing the current production mode of remanufacturing industry, i.e., size repair or replacement method. The rate of utilization of waste products can be improved, and the resource efficiency of remanufacturing industry can be advanced.
(2) Develop automated remanufacturing technology to meet the requirements of mass production.

One of the important features of remanufacturing relative maintenance is the batch and scale of the production object. Therefore, the remanufacturing production line needs remanufacture batches of products, which requires further development of automatic remanufacturing technology to promote the production efficiency. For example, by using robot and automatic control technology, the application of automatic plasma spraying technology in remanufacturing is realized.

(3) Develop flexible remanufacturing technology to improve the adaptability of the variety of remanufacturing products.

The traditional remanufacturing production plan of large batches of products will gradually be replaced by that of small batch, variety and personalized products. In addition, the rapid changes in market demand make the traditional remanufacturing production based on recovery experience gradual transition to the remanufacturing mode of performance improving and recovery. Therefore, the use of a large number of flexible equipment and production process in the remanufacturing production line can quickly make the remanufacturing production adapt to the changes in the blank products and production targets to achieve rapid flexible production.

(4) Develop green remanufacturing technology to reduce the pollution discharge of remanufacturing production.

Remanufacturing engineering have significant effects on energy saving, material saving and environmental protection, but "three wastes" emission problem exists for the specific remanufacturing technology, such as cleaning products, coating and surface brush plating in the manufacturing process, leading to a certain degree of pollution. Therefore, it is necessary to further develop physical cleaning technology, reduce the use of chemical cleaning methods, and develop some environmentally friendly plating solution. At present, in remanufacturing engineering field, further attention to environmental protection is needed. Cleaner production mode and green remanufacturing technology should be extensively used to realize the target of comprehensive utilization of "three wastes".

(5) Develop intelligent remanufacturing technology to improve the efficiency of remanufacturing production.

The development trend of intelligent remanufacturing technology mainly includes three aspects. Firstly, it is the intelligent design of remanufacturing process. For the specific parts and components, the optimization design of remanufacturing forming technology can be realized based on the expert database information. Secondly, it is the intelligent control of the remanufacturing forming process. Automatic optimization of process parameters and control parameters can be realized based on the remanufacturing forming process of parts and components. Thirdly, it is the 
intelligent detection of remanufacturing equipment and parts. Rapid nondestructive detection technology, such as eddy current testing, ultrasonic testing and laser monitoring which can realize real-time grasp of remanufacturing forming process stability and state of remanufacturing forming parts process in the remanufacturing process can be used to maximize avoiding unqualified parts of remanufacturing forming.

\section{Development strategy of green remanufacturing industry}

In the next 15 years, remanufacturing must face the difficulties, cope with challenges, and break through the bottlenecks. We should seize the present opportunity and achieve a major breakthrough in the remanufacturing industry. We focus on the breakthrough of five key technologies, improvement of four support systems, formation of three key areas, establishment of two engineering centers, and formation of a number of leading industries (Xu, Shi, Zheng, \& Li, 2015).

Firstly, to break through five key technologies: Remanufacturing system planning and product design technology, performance evaluation and life assessment technology for waste products, green and high efficiency cleaning and dismantling technology, adding material remanufacturing technology, and safety testing technology for remanufacturing products. Secondly, to improve four support systems: Recovery system of waste parts, industry standard system, environmental safety system, and circulation service system. Thirdly, to form three key areas: Remanufacturing of transportation equipment, remanufacturing of industrial production equipment, and remanufacturing of high-end smart equipment. Fourthly, to establish engineering centers including the research center of remanufacturing engineering and the quality inspection center of remanufacturing products. Fifthly, to form a number of leading industries including green manufacturing industry group of perfect scale and international leading remanufacturing enterprises.

(1) Recent development strategy

The main researching objectives of remanufacturing include cars, construction machinery, and their spare parts such as waste shaft, gear, and box. Meanwhile, some large industrial equipment is also studied. The research of remanufacturing technology and setting capacity of remanufacturing standard of equipment components will be gradually improved. The application system of equipment remanufacturing engineering will be also improved. The remanufacturing rate of used machinery parts reaching $60 \%$, the industrial scale and the employment scale of remanufacturing reaching $2 \%$ and $5 \%$ of the manufacturing industry, respectively, are tried to be realized.

(2) Medium-term development strategy

The objects of remanufacturing equipment include energy equipment, high-end numerical control machine, and power machinery. The industrialization of remanufacturing technology will be accelerated. The large-scale remanufacturing industry group will be formed. The remanufacturing rate of used machinery parts reaching $70 \%$, the industrial scale and the employment scale of remanufacturing reaching $5 \%$ and $10 \%$ of the manufacturing industry, respectively, are tried to be realized.

(3) Long term development strategy

The objects of remanufacturing include high-end transportation equipment such as airplane, ship and highspeed railway, complex and expensive equipment such as steam turbine used in water conservancy generating set and nuclear power generating set, as well as electronic equipment used in medical, household, and office filed. The remanufacturing rate of used machinery parts reaching $80 \%$, the industrial scale and the employment scale of remanufacturing reaching $10 \%$ and $20 \%$ of the manufacturing industry, respectively, are tried to be realized. Besides, diversified industrialization achievements with international competitive power will be achieved. Many world famous remanufacturing enterprises and remanufacturing agglomeration industrial zone will be established to form the scale effect with certain international influence.

\section{Conclusions}

The innovative remanufacturing industry mode with the features of "supported by new and high technology, based on the surface engineering technology to restore the size and enhance the performance, combining of production and research, re-cyclic and economic" has formed in China. Remanufacturing meets the requirement of development strategy of constructing the ecological civilization which was proposed in the 18th National Congress of the Communist Party of China. Remanufacturing is one of the important technical supports for the recycling economy, so the important role and key technologies of remanufacturing will be the focus of development in the next 20 years. China is a big country of manufacturing and using equipment, so a large number of equipment has entered the peak period of scrap. The development of remanufacturing industry not only has significant economic benefits, but also has significant social benefits. With the country's emphasis, China's remanufacturing industry will achieve leapfrog development in the future.

\section{References}

\footnotetext{
Li, E., Shi, P., \& Xu, B. (2015). Analysis of policies and regulations of China remanufacturing. Journal of Mechanical Engineering, 51(19), 117-123 (in Chinese).

Wang, X. (2015). Demystifying made in China 2025: From the large
} 
industrial country to the powerful industrial country. Beijing: China Machine Press (in Chinese).

$\mathrm{Xu}, \mathrm{B}$. (2007). Remanufacture and recycling economy. Beijing: Science Press (in Chinese).

$\mathrm{Xu}$, B. (2013). Equipment remanufacturing engineering.Beijing: National Defense Industry Press (in Chinese).

$\mathrm{Xu}$, B., Dong, S., \& Shi, P. (2013). States and prospects of China characterized quality guarantee technology system for remanufacturing. Journal of Mechanical Engineering, 49(20), 84-90 (in Chinese).

Xu, B., Dong, S., Zhu, S., \& Shi, P. (2012). Prospects and developing of remanufacture forming technology. Journal of Mechanical Engineering, 48(15), 96-104 (in Chinese).

Xu, B., Shi, P., \& Liu, B. (2012). Engineering management problems of remanufacturing industry. China Surface Engineering, 25(6), 107111 (in Chinese).

Xu, B., Shi, P., Zheng, H., \& Li, E. (2015). Engineering management problems of remanufacturing industry. Frontiers of Engineering Management, 2(1), 13-18.

Yang, T. (2014). Promote the healthy and orderly development of remanufacturing industry in China. China Surface Engineering, 27 (6), 1-3 (in Chinese). 